\title{
The Emancipatory Project
}

of Posthumanism

Erika Cudworth and Stephen Hobden 


\section{Table of Contents}

Acknowledgements

Chapter 1 Introduction

Chapter 2 Emancipation and its Critics

Chapter 3 A Politics of Enchantment: the power and fragility of things

Chapter 4 A Politics of Attachment: actor-network theory

Chapter 5 How to Change a Complex World

Chapter 6 Critical Posthumanism and the Lives of Others

Chapter 7 From the Imperial Human to Creaturely Politics

Chapter 8 For Posthumanist Emancipation - a Terraist Manifesto

Bibliography 


\section{Acknowledgements}

Since Posthuman International Relations (Zed, 2011) our adventures with the posthuman have led us along various trails. Some of the places we have been and things we have said feature here in various states of revision and (re)composition.

The 2012 Millennium Conference at the LSE, with a focus on new materialism in International Relations, was a starting point for us when we first gave the paper on posthumanism and agency that became 'Of Parts and Wholes: International Relations Beyond the Human' (2013, Millennium Journal of International Studies, 41, 3: 430-450). Arguments made here appear in Chapters 3 and 6, in discussions of non-human animal agency. It was here that we were inspired by the interest in new materialist approaches and also engaged (face-to-face!) with some critics. These include David Chandler, who took our rather full-on response to the critique he made in Millennium 41 -- 'Liberation for Straw Dogs? Old materialism, new materialism and the challenge of an emancipatory posthumanism' (2015, Globalizations, 12, 1: 134-148) -- with characteristic grace and good humour. That paper features across the book (particularly in Chapters 1 and 3) and was the inspiration for this book project. Our thanks are also due here to Chris Rossdale, for including the paper in the special edition of Globalizations that he complied. We would like to thank David for his continued engagement with our work and for prompting us to respond with him to the problem with liberal framings of responses to the existential crises we face in "Are we all just prisoners here, of our own device?' A response to 
Burke et al's Planet Politics' (forthcoming). The arguments made here feature in the final chapter, where we present a rather different 'Manifesto'.

In thinking about 'creatureliness' in Chapter 6, we rework some of the material from 'Civilization and the Animal' (2014 Millennium Journal of International Studies, 42, 2: 746-766), and this also pops up in Chapter 1. In thinking about the future in chapters 6,7 and 8 , ideas from various other papers appear, such as 'The Posthuman Way of War' (2015 Security Dialogue. 46, 6: 513-529) and 'Anarchism's Posthuman Future' (forthcoming in Anarchist Studies 2017/8). Here our ideas have benefitted from the engagement of Claudia Aradau, Beate Jahn and Ruth Kinna, as well as anonymous reviewers.

We would also like to thank our respective partners, teenagers and other critters-in-the-home, for putting up with more writing. 


\section{Chapter One}

\section{Introduction}

\section{An Inhospitable Place to Start}

Rob Walker began his pathbreaking 1993 book Inside/Outside with a reference to an old 'Celtic' joke, the punch line of which was 'the inadvisability of starting from "here" (Walker, 1991: ix). His reference was to the condition of International Relations theory, which he considered to be less than congenial to the form of analysis that he was presenting. The punchline to that particular joke comes back to mind as we begin this book. Not only has the discipline overlooked the changing geopolitical situation, it has also failed to address a mounting economic and political crisis at a global level, and the escalating evidence that life on the planet is facing a system-wide catastrophe.

That International Relations has 'failed' as a discipline, is far from an original claim. It would be hard to argue though that given the upcoming centennial anniversary of the founding of the first Department of International Politics in Aberystwyth, that it has contributed much to understanding and mitigating international tensions. The two dominating perspectives on the operation of international politics appear to have less and less to say about the events that we are confronting. Realism seems to have something to contribute to understanding mounting global tensions and will claim a victory if the EU collapses, as many are now starting to predict. But can Realism help 
with understanding issues such as the increasing significance of global corporations, environmental damage and the wave of political violence that is occurring? An image of the world that prioritises state interactions as the key to understanding global processes, and whose most significant contribution to knowledge is that the world is most peaceful when there is a balance of power, would appear to have little to contribute in confronting such issues. Likewise, Liberalism, whose progressive view points towards the possibilities for state co-operation, and the global benefits of international trade would appear to be faced with its own problems in the face of rising nationalism, and the stalling of global trade following the 2008 economic crisis. The prescription from the two mainstream approaches would thus appear to be more of the same. For Realism, notions of an other world are inherently idealist and downright dangerous. For Liberalism, the prescription is more of the medicine which has got us into this mess in the first place. The Liberal literature appears to be almost complacently optimistic at a time when economic and political processes seem to be under considerable strain.

The various forms of critical theory have succeeded in shining some light into areas of international life that state-focussed realist and liberal perspectives have obscured. Feminist theory, in its various manifestations, has perhaps been the most successful here, in highlighting the many roles played by women in international politics, but also in forcing a reconsideration of the ontological and epistemological foundations of the discipline. Postcolonial theory has also had an impact in bringing a focus to relations between North and South, and in highlighting the continued effects of the colonial period for both the colonised and the coloniser. Where critical approaches have been less vocal is in advocating processes by which this world might be other. 
So while critical approaches have done much to highlight the marginalised and the processes by which that marginalisation occurs, they have been less attentive to how the distribution of economic and political power might be made more equitable. As Milja Kurki was prompted to reflect: 'it really is rather disappointing for - and a disappointing symptom of - alternative, or so-called 'critical', thinking in the social sciences that even when the problems of the dominant model are evident, there is no real systematic, effective or realistic opposition to it' (Kurki, 2011: 130).

What then of the world outside of the prognostications made by theorists? Our own particular concerns are human relations with the rest of nature. However, it is important to acknowledge at the outset that we don't see any resolution to ecological problems that doesn't address, either in combination or parallel with, the glaring inequalities in human well-being. With regard to the latter, while there have been improvements in income at an average level this has occurred alongside mounting income inequality at both a national and global scale (see Hickel, 2016).

We won't repeat here the growing litany of ecological problems. These are discussed at much greater length elsewhere (see for example Emmott, 2013; Hamilton, 2010; Hansen, 2011; Kolbert, 2014; Scranton, 2015). There are a couple of general points we would like to focus on. First, by whatever measure one chooses to use we are moving in the wrong direction. New evidence seems to appear every day indicating that the processes and impacts of climate change are happening at much faster rates than was previously anticipated. The timescale in which to avert catastrophic climate change is becoming ever shorter. Despite the apparent success of the Paris 2015 climate change summit in committing to a maximum of 1.5 degrees of planetary warming, there is little evidence of action being taken to enable temperature rises to 
be limited to that level. For example, in the UK, the subsidies to the fracking industry and the removal of grants to encourage the installation of solar power panels would appear to have the opposite impacts from what was agreed in Paris. One means of measuring these changes has been introduced by researchers at the Stockholm Resilience Centre. They have pointed to nine planetary boundaries which need to be maintained in order to permit a flourishing and sustainable level of human life. The concept of planetary boundaries was first advanced in 2009 and has been the basis of considerable research since then. In an update, (Steffen et al, 2015) the claim was made that four of these thresholds had already been breached: climate change; loss of biosphere integrity; land-system change; and altered biogeochemical cycles. Of these four, two are considered by the researchers to be 'core boundaries'. These are limits that would result in driving the earth system into a new, and potentially less benign, state. Such a condition would exacerbate existing problems including sustainability and poverty reduction, affecting many parts of the world, both developed and less developed.

An alternative measure of the human impact on the planet is the ecological footprint. The ecological footprint is a measure of the amount of resources used by humans and the pressures that we exert on the global environment. It measures how fast we consume resources and generate waste compared to nature's capacity to reproduce resources and absorb waste. This is expressed as a global hectare. A global hectare is an accounting measure and refers to the area that an individual requires to reproduce their particular lifestyle. This can be compared to the amount of area that is available on the planet. Averaged out across humanity each of us has 1.7 global hectares available to supply our needs and absorb our wastes. By calculating the number of 
global hectares each of us requires to sustain our lifestyles we can calculate the discrepancy between our way of life and planet's capacity to maintain that. In 2010, humanity's total Ecological Footprint worldwide was 18.1 billion global hectares (gha); with world population at approximately 7 billion people, the average person's Footprint was 2.6 global hectares. But there were only 12 billion gha of biocapacity available that year, or 1.7 gha per person. This overshoot of approximately 50 percent means that in 2010 humanity used the equivalent of 1.5 Earths to support its consumption (WWF, 2014: 33).

These figures can be broken down by society. Just five countries make up nearly $50 \%$ of the total ecological footprint. In ranked order, they are China, the US, India, Brazil and Russia. However, note that the per capita footprint of four of those countries is much lower than that of the US. China is ranked $76^{\text {th }}$ in terms of its per capita ecological footprint, but because of its large population when taken as a total it has the largest ecological footprint of any country. At a per capita level Indian citizens have a sustainable ecological footprint, below 1.7 gha, however again because of the large population, at a national level India has the third largest national ecological footprint. The US has approximately a quarter of the population of China, but because its per capita footprint is much higher, its total is nearly the same as that of China. If everyone on the planet consumed resources at the rate that US citizens do then we would need 3.9 planets. The US is not the highest though. If we all consumed resources at the same rate as citizens of Qatar, then we would need 4.8 planets. One useful way of using the statistics has been to combine them with the UN's Human Development Index so that demand on the planet's resources can be matched with elements of the index that includes life expectancy, education and income. 
Combining these two measures points to a quadrant that combines a high level of human development (above 0.8), with a sustainable degree of consumption. A number of countries fulfil one or other of these criteria, but very few have achieved both - and in 2010, none. One problem that the human species confronts is that as global population increases the gha per person shrinks - the central reason why, for Stephen Emmott, population levels will be the drivers of a soon to come ecological crisis and likely civilizational collapse (Emmott, 2013: 38).

The second general point that we would like to make relates to the rate at which humans as a species are responsible for the depletion of other species. Species loss is one of the planetary boundaries highlighted by the Stockholm Resilience Centre, and there is considerable evidence to suggest that human activity is responsible for what has been labelled the sixth great extinction (Kolbert, 2014). There is another way in which humans 'consume' our fellow species, and that is through the processes of industrialised agricultural production. According to the Worldwatch Institute, 56 billion animals are slaughtered each year as part of food production processes. Many of these animals lived their lives on factory farms in terrible conditions. This figure does not take into account the quantity of fishes and other aquatic creatures caught each year. There are a number of problems with estimating the numbers, but one estimate, based on data from the United Nations Food and Agriculture Organisation estimated the range to be between 37 and 120 billion individual fish per year.

This level of carnage indicates the character of the relationship between humans and the rest of nature. It is one that is entirely instrumental - seeing the rest of nature simply as a resource to be exploited, but yet also with the illusion that it is an 
inexhaustible resource. This resource will not only keep supplying us but will also be able to absorb all our waste products - whether garbage or greenhouse gases from the burning of fossil fuels. There are ethical arguments for altering our behaviour towards the rest of nature - that other forms of life and landscapes have an inherent value that we shouldn't undermine. There are also quite simple self-interested arguments for altering our relations with the rest of nature, because we are destroying the support systems that we need to survive on the planet. Regardless of which view we hold, and it is entirely possible to hold both, it is evident that there is a need for a change of practice in our interactions with the rest of nature. In the early twentieth century it would appear that humanity is in a fix. It is our argument though that all is not lost, at least, not yet. Not only is change possible, but there is also evidence to suggest that change is occurring. Thus far the change is happening too slowly. However, the instances that suggest those other ways of thinking and acting concerning human relations with the rest nature indicate that that change could occur on a much wider basis. It is, we argue, necessary for there to be a change at the level of human consciousness, in how we think about our relations with the rest of nature.

\section{Posthumanism}

We have adopted the term posthumanism to describe our theoretical framework. While the term does fit our viewpoint, it comes at a cost. The cost is that the term has been used in a variety of different ways, which has and does lead to confusion. While posthumanism remains a relatively marginal approach in International Relations, it has made a considerable impact in other areas of the study of the social world, particularly in Sociology. What is perhaps more surprising is that the mainstream media is suffused with images of the posthuman, in all the varieties of ways in which 
it has been understood. Given the wealth of examples, we will draw on the popular media to illustrate the various ways in which posthumanism has been understood. The term posthumanism has been used in three principal ways: in the sense of a world after humanity, as forms of body modification and transhumanist 'uplift', and, our own usage, a world comprised of the more than human. Questions of what constitutes the posthuman have been a regular feature of fiction and the movies. In some ways there has been a deeper engagement with these issues in fictional treatments rather than academia. Questions about the character of what it is to be human and the conditions of various societies where 'civilisation' has collapsed have frequently been investigated in literature and film.

Posthumanism has been used in the sense of 'after humanity'. Dystopias of various kinds have become a mainstream element in popular literature (particularly so-called young adult literature) and in the movies, with the Hunger Games trilogy being a famous and influential example. The current popularity of this genre perhaps reflects societal fears of a civilizational breakdown - possibly as a result of climate change, or nuclear conflict. Such concerns have a long history, dating back to at least Orwell's 1984 and the future society described in Aldous Huxley's Brave New World. A compelling and much lauded contemporary example is Margaret Atwood's Oryx and Crake, set at a point some way into the future, where a character called Snowman is contemplating the devastated landscape around him and his own situation as probably the last man on earth after a genetically engineered disease has wiped out the human. The novel is a gripping tale of Snowman's struggles to survive in a world populated with genetic mutations of species and in the face of his gradual starvation. We have, of course, a human narrator, Snowman, and his previous incarnation as a naive young 
man called Jimmy. Jimmy watches as the world hurtles towards catastrophe masterminded by his over-ambitious genius scientist friend, Crake. The book's frame is the potential of science to create genetic chaos if the only constraint on developments was financial, something that critics pointed out is closer to realisation than we may care to think (Magazine, 2011). Pigoons (a combination of pig and human genes) provide fast grown organs for human transplant, wolvogs (wolf/dog hybrids) make hyper-effective guards and ChickieNobs replace chicken meat from hens. Jimmy is the conduit for Atwood's concern as seen here in his first encounter with the prototype hen-replacement in Crake's laboratory:

'This is horrible,' said Jimmy. The thing was a nightmare. It was like an animal-protein tuber.

'Picture a sea-anemone body plan,' said Crake. 'That helps.'

'But what's it thinking?' said Jimmy.

The woman gave her jocular woodpecker yodel, and explained that they'd removed all the brain functions that had nothing to do with digestion, assimilation, and growth...

'No need for added growth hormones,' said the woman, 'the high growth rate's built in. You get chicken breasts in two weeks - that's a three-week improvement on the most efficient low-light, high-density chicken farming operation so far devised. And the animal-welfare freaks won't be able to say a word, because this thing feels no pain' (Atwood, 2003: 202)

Herbivorous humanoid creatures, with little interest in violence or sex and conveniently ultra-violent light resistant skin - Crakers - are developed as a desirable 
alternative to murdering, raping, war-making, planet-wrecking humans, who are then destroyed. These examples are not truly posthuman however -- though they point to concerns that current trends may result in societal breakdown resulting in eventual human extinction. Cormac McCarthy's The Road perhaps comes closest to the depicting a societal breakdown indicating a possible end of humanity.

Movies depicting a posthuman world are, unsurprisingly, an extreme rarity -- given the apparent need for a human focus in the process of narration. Something closer to a posthuman world has been depicted in movies where the protagonists discover a depopulated planet which is actually Earth. The original Planet of the Apes movies played with this idea -- although again not truly a posthuman world as the human population has become a form of sub-species, used by the ruling apes as pets and for use in medical experiments. The idea of discovery of a depopulated planet also appears in the more recent, critically panned film After Earth where a previously abandoned earth is re-visited by humans. Again, however, the film is from a human perspective.

Perhaps the most successful attempt to depict a posthuman world (though not a posthuman universe, as again the survivors have abandoned the planet) is the animated film WALL-E. The initial phases of the film are entirely from the perspective of a robot left with the role of tidying up a planet made uninhabitable by the quantity of human detritus. This robot is particularly interested in collecting human artefacts, and for some unexplained reason is particularly drawn to the movie 'Hello Dolly'. While the movie WALL-E perhaps goes furthest in exploring a posthuman world, it also explores another long established question investigated in the movies; what does it mean to be human? While humans exist in WALL-E, they are a rather pathetic bunch 
who have evolved into creatures who can barely move of their own volition. WALL$\mathrm{E}$ is by far the most human character in the movie and displays human attributes, though mainly love for another robot -- Eve.

The film WALL-E then crosses over into a second form in which the term posthumanism has been utilised. This is the issue of transhumanism - the implications of various forms of body modification have in questioning the boundaries between the human and non-human. This issue has been one that the movies have returned to frequently. Perhaps most famously in Bladerunner, but more extensively in the various representations of Mary Shelley's novel Frankenstein, though also taking the robot version of Maria in Fritz Lang's Metropolis. While not a movie, the treatment of the human / non-human border is a question that has been addressed in the British television series Humans. As with WALL-E, in Humans, it is the 'synths' who appear to be more human than the human characters. It is perhaps also worth noting that there is very much a gender issue in much of these depictions with robots such as Maria in Metropolis, Mia in Humans, and perhaps more overtly Lisa in Weird Science, appearing to be in the form of a male fantasy of a perfect woman.

While these issues have been reflected in the posthuman literature, we use the term in a third, and different form -- to take into account the 'more than human' character of human existence. Again, this is a question that has been explored extensively in the movies. Both the original version, though more particularly the re-booted, Planet of the Apes raises questions about relations between human and non-human species. However, Jurassic World explores these issues in ways which reflect our own particular interests. Forget for a moment the implausibility of re-populating the world 
with dinosaurs, and accept the films starting supposition that this is entirely reasonable. The premise of the film is that human tinkering with nature to create a more fearsome dinosaur the Indominus Rex upsets a normal balance within the dinosaur park. The new dinosaur is required because of the need to keep innovating in the park to maintain visitor numbers (a subtle criticism of the costs of capitalism's requirement for constant innovation). However, the complex mixture of genes used to create the Indominus Rex produces a creature with unexpected emergent features -- a particularly violent though highly intelligent dinosaur. The creature is of particular interest to the military (a not so subtle criticism of militarism). Meanwhile, the film's central character, Owen, is involved in training a group of velociraptors. It is clear that Owen has a close relationship with the velociraptors though it is unclear to what extent this relationship extends until the final (and inevitable) conflict with the Indominus Rex. In the closing reel, the velociraptors choose to side with the humans against the genetically modified dinosaur - indicating the existence of what we would describe as a posthuman community including Owen and the predators. Stability in the park, however, is only re-established when a Mosasaurus, a gigantic undersea lizard consumes the Indominus Rex. Forces beyond human control thus ultimately reestablish a natural balance.

Films such as Jurassic World explore the boundaries of human / non-human relations and in some ways illuminate the themes that we are concerned with in developing a posthuman international relations. While the unpredictable outcomes of action in a complex world play a significant role in the plot (the mixture of genes in the engineered dinosaur interact to produce unanticipated and de-stabilising results), our particular interest is the significance of human relations with other species. The 
development of a relationship with the velociraptors can be viewed as a posthuman community, where inter-species relationships are other than simple control, domination and exploitation.

In our previous work we have built on a foundation of complexity theory to develop a perspective of a world made up of multiple complex adaptive systems. We drew in particular on the work of the French sociologist Edgar Morin (2008) whose conception of generalised complexity suggested the need for a total epistemological re-think. Ultimately, for Morin, the world we inhabit is unpredictable, and we need to become skilled at living with complexity. Complexity thinking we suggested was an appropriate tool for analysing international relations, a sphere of activity which appears to be characterised by the unexpected. This viewpoint sees the international system embedded in a number of complex systems, ultimately both human and nonhuman, animate and inanimate. The term 'posthuman' provided a good indication that we saw the world as 'more than human'. If we want to analyse international relations our understanding will be incomplete if we overlook human relations with the rest of nature. For us, the clearest indication of this was the failure to acknowledge the role of nonhuman animals in the conduct of warfare - an activity that would have been inconceivable for much of human history without the forced participation of our fellow species (Cudworth and Hobden, 2015).

The term posthumanism was also one that we found appropriate to describe our perspective as a signal that we regarded our work as a move on from humanism. We use posthumanism not as a total rejection of humanism, but as a way of indicating our dissent from certain elements of humanism. While humanism is not a stable concept, 
we would want to reject humanist ideas that see the human species as in some way unique, exceptional, essential or in some way distinct from the rest of nature. Such a view, for example, is evident in this definition of humanism suggested by Hasana Sharp, 'a philosophical tradition that aspires to a universal union of humanity on the basis of a shared characteristic that is not exhibited by nonhumans, like reason, morals sensibility, or a capacity for autonomy' (Sharp, 2011: 5). In a similar way, Donna Haraway has summarised such a view as 'the premise that humanity alone is not a spatial and temporal web of interspecies dependencies' (Haraway, 2007: 11). Our conception of a world made up of intersecting and overlapping complex adaptive systems is the basis for our rejection of these elements of humanism.

\section{Ecological crisis and the Anthropocene}

There is a growing body of literature which suggests that we are at critical point for the human species in its relations with the rest of nature. This has been summed up most directly by Stephen Emmott, 'I think we're fucked' (Emmott, 2013). Making a very similar argument, though rather more elegantly, James Lovelock has observed that 'the bell has started tolling to mark our ending... only a handful of the teeming billions alive now will survive.' (Lovelock, 2006: 147) Such comments are at perhaps the extreme end of the literature, though even more cautious writers assume that we are unlikely to get through the next 100 years without major upheavals (Gore, 2013; Rees, 2003). For many, this crisis has been encapsulated by the increasing popularity of the term 'Anthropocene' to describe our current situation.

In 2000, Paul Crutzen and Eugene Stoermer proposed 'to use the term

“Anthropocene” for the current geological epoch' (Crutzen and Stoermer, 2000: 17). 
This word, they claimed, would best capture the ways in which the extent of human activity (in terms of population growth, consumption of fossil fuels, emission of greenhouse gases, speed of species extinction and so on) has meant that we have written ourselves into the geological record on such an unprecedented scale that we have given rise to a new geological epoch. Crutzen, writing of the 'Geology of Mankind', suggested that the scale of anthropogenic effects has a relatively brief history -- beginning with the Industrial Revolution in England at the end of the Eighteenth Century (2002: 23). It is important to note that this term has not been officially sanctioned within geology and that within the discipline, remains disputed and somewhat political (Autin and Holbroke, 2012; Steffan et al, 2011). Nevertheless, Jan Zalasiewicz and others consider that the concept has incredible potential (Zalasiewicz et al, 2011) because in enables us to think of the interplay of both the social and the natural, and because the current stakes are so high, we require a politicised geology. Zalasiewiz, writing with Williams, Steffan and Crutzen, argues that urbanisation deserves special attention as a phenomenon that has become 'geologically unique' in refashioning life on earth (Zalasiewicz et al 2010: 2230).

Unfortunately in current social science, there seems to be an uncritical endorsement of our contemporary condition in terms of the 'Anthropocene' wherein 'humanity' through industrialisation and urbanisation - has altered the biophysical conditions of life (Burke et al, 2015). However, the focus on anthropogenic global warming often elides other challenges that the notion of the Anthropocene throws up. As the Human Animal Research Network Editorial Collective (HARN, 2015: viii) point out, Crutzen and Stoermer's original articulation raises key questions of human relations with other species - those of extinction, industrial fishing and animal agriculture. Dipesh 
Chakrabarty (2009) considers that a key problem with the way in which the Anthropocene is conceptualised is that it focuses on an imperilled planet as a result of human lifeways, rather than an imperilled humanity. However, this limited critique understands the 'human' as a singular entity. It also is anthropocentric in failing to see that the Anthropocene is a risky concept - it suggests anthropogenic destruction is an inevitability given humanities 'super-natural' nature (HARN, 2015: ix). We are indeed become death, the destroyer of worlds; and also, perhaps, the makers of worlds. The Anthropocene also suggests further that given the irreversibility of such destruction, humans are to be relied on for transcending such problems through technology (Christ, 2013). In this sense, the Anthropocene can be understood as a discourse which confirms humanities pre-eminence. The Anthopocene concept is wedded to human agency and human exceptionalism while being seen to undermine both. As Florence Chiew (2015: 3) surmises:

...by emphasising the unprecedented dominance of human activity in scarring the landscape, the Anthropocene is by definition wedded to a position of human exceptionalism...the question of what constitutes intervention and agency in the Anthropocene is not only human-centred, but paradoxically selfreferential.

What the Anthropocene implies is that the cause of the current malaise is also the only hope for intervention - how 'god-like' is human power (Cohen, 2012: 240). Chiew rightly suggests that it is this 'self-evidence' of the human as an architect of geology or nature that needs rethinking (2015: 14). Rather, Drawing on Karen Barad's understanding of the human as being a part of the world we seek to understand (2007: 
185), Chiew argues that we require a deeper sense of entanglement and relationality with systemic processes of socialnature. What drove 'us' - the collective human - to be so destructive and dangerous a species? The answer to this, in the formulas of Crutzen, Zalasiewicz and others is the collective human quest to be emancipated from nature. This 'Geostory', as Latour (2013) puts it, is a counter story to the moderns who seek to free themselves from material hindrances. Yet how accurate is this story of human intervention in the deep time of the earth?

Writing in the HARN collection along with Chiew is Agata Mrva-Montoya, who raises the important question of whether the definition of the Anthropocene fits with such recent history. Rather, she argues that archaeological research demonstrates that humans were making large scale transformations of the Earth's eco-system very many thousands of years earlier. Taking Cyprus as her case study, she argues that humans had a profound effect on terrestrial species through which they have long engineered nature. All Cypriot species, she suggests should be understood as 'introduced' - there is no authentic ancient, rather, there are anthropogenic interdependencies from antiquity until the present (Mrva-Montoya, 2015: 54). Likewise, Adrian Franklin (2015: 64) portrays humans as 'planet-changers' at least from the late Palaeolithic. What we often consider to be 'native ecologies' are rarely any such thing. Rather, they have been extensively modified, and this is particularly so in colonialist settler societies, such as Australia where both landscapes and ecosystems are projects of nation building. Emphasising the problematic casting of feral animal species as 'unnatural' and unnationalistic, Franklin argues that our histories of co-evolution raise serious questions for the 'entire conceptual edifice of the Anthropocene holds up a supremacist view of human agency against a largely passive and frail nature' (2015: 
83). It is certainly worth emphasising that the mutualistic relations between a whole network of life forms are what make Earth habitable for more 'advanced' creaturely life in the first place. And such non-human species are also active in changing environments in relatively short spaces of time as Michael Hathaway's studies of elephants in rural China suggests. Rather than understanding such creatures as victims (of human hunters) or as challenging human lifeways (by eating crops, for example) (2015: 226), he suggests that understanding such creatures as minded, inquisitive, pleasure-seeking and problem solving dwellers in shared territory, we might face environmental and other challenges as co-participants with non-human species in a multi-species world.

A more positive assessment would suggest that the Anthropocene at least enables some kind of reflexivity on the notion of the human, re-imagining ourselves (Chakrabarty, 2009). Yet the Anthropocene cannot escape its human supremacism, ahistoricism and denial of a fractured, differentiated humanity. In our work on Posthuman International Relations, we were at pains to emphasise the risks in a conflated conception of 'humanity', and of course the Anthropocene engages in such conceptual conflation by suggesting that 'humanity' is a force of nature that is singular. Rather, as many have pointed out, we might characterise our current condition as one produced by the lifeways of a distinct social and geographically defined group; a subset of humanity. Thus terms such as the Capitalocene (Moore, 2015), the Anthrobscene (Parikka, 2015), Oliganthropocene (Gemenne, 2015), the Manthropocene (Raworth, 2014) and the Plantationocene have been used to make clear 'who' and what practices are responsible; while the difference-embracing Chthulucene (Haraway, 2015) understands us as enmeshed through tentacular 
practices and entreats us to 'make kin' as the mechanism for delivering multi-species eco-justice. Singular humanity is a dangerous trope when there is intra and extrahuman justice work to be undertaken.

Haraway argues that the Capitalocene in particular is a more appropriate analytic vehicle for understanding our present condition, but she acknowledges that in all our socialnatural formations questions of difference are 'there, from the get-go' (2015: 223). She argues, following the biologist Scott Gilbert, that the Anthropocene may be a boundary event rather than an epoch, one that is short lived (see Haraway et al, 2016). What is needed is to think beyond, at future possibilities of the death of the human (and many other critters) or whether, in these times of destruction (some) humans might find ways of forming alliances and promoting partial healing on a damaged planet. She is right - this is the task and ours, here.

Whether or not we use the notion of the Anthropocene as a more or less accurate descriptor of our current condition, it seems evident from discussions of the condition of the planet that we can't go on as we are, and that either we need to make some major changes in our behaviour -- which will be painful, or changes in our behaviour will be forced upon us -- which is likely to be both more painful, and the impacts of which will be more widely felt.

\section{Change and Complexity}

As we have already noted, there seems to be little, and perhaps diminishing, enthusiasm for making the scale of lifestyle changes that will be required to avert major climatic change. In addition to a lack of enthusiasm, there is the sheer difficulty 
of implementing change in a complex world. Our adoption of complexity thinking as an underlying framework of analysis and its association with the inherent notion of unpredictability opened our work to criticism. In a discussion of our argument, along with others considered to be in a 'new materialist' perspective, David Chandler argued there was a celebration of human embeddedness in the rest of the human and non-human world. For Chandler, the New Materialists engage with an ethics of becoming, where knowledge can only illuminate what is happening rather than predict what is to come. For Chandler (2013b: 527), this is 'far too high' a price to pay, and one for which 'the prize on offer is a false one'. The reason for this, Chandler (2013b: 528) argued is because it removes our subjectivity as human beings, 'we can never be human subjects, collectively understanding, constituting and transforming our world'. New materialist approaches suggest that we live in a world of becoming, where it is the connections and inter-relations that take priority. As a result, the ontological focus is 'objects transforming objects - rather than subjects transforming objects' (Chandler, 2013b: 529).

There are two interrelated implications that Chandler highlights. First is that we are subject to the 'rule of blind necessity', where our options become those of a micro politics, the transformation of the self as a more ecologically aware embedded being. Second, and most importantly, this move, Chandler claimed puts us beyond the world of the knowable. Drawing on Hannah Arendt, who argued that the world that could be understandable marks the limits of what we should consider, he argued that the unpredictability implied by New Materialism leads to 'a desert', and as such removes 'the meaningfulness of the world itself' (Chandler, 2013b: 534). When we lose the possibility of engaging meaningfully in the world 'we lose the freedom of the goal- 
determining subject' (Chandler, 2013a: 18). The increasing influence of postmaterialist and posthumanist thinking means that:

Without social struggle and the social understandings it gave rise to, the modernist edifice is rapidly disappearing. The world appears to lack the imprint of human construction and therefore to be 'post-human'. We are reborn or born-again in a world in which we appear to be without the signposts of modernity. Today's sensibilities mean that we are much more likely to be drawn towards globalised understandings of complexity, captured well in physicist Ilya Prigogine's view of complexity as 'the irreversible succession of events' where 'the arrow of time' ensures that circumstances are never stable for repeatable cause-and-effect relations, destabilising any possibility of acting on the basis of knowable eternal or fixed 'natural' laws (Chandler, 2013b: 520).

In a world where the predictability of our actions is limited, we become incapable of action. As Chandler (2013b: 525) argues, 'if we imagined that we could never possibly know in advance, or at the time, of our actions or decisions, however minor, what their final or ultimate ends or outcomes would be, we would become incapacitated or paralysed'. Human freedom is only possible through the overcoming of necessity, and for this, Chandler (2013a: 6) argues we need fixed understandings: 'it is through these fixed structures of meaning that we understand ourselves as able to master necessity - the relations of cause and effect'. 
Jessica Schmidt also argues that we have underplayed the significance of human subjectivity. While it is human agency that is the cause of exploitation of the nonhuman, the call for a re-ordering of human - non-human relations, Schmidt suggests, removes the very element of human agency that could reverse the situation. She argues that 'in this way, undoing the human specificity of the political subject as a means to criticize it leaves us without any means to locate and make sense of, let alone critically engage with, social injustice, persistent inequality and man-made environmental degradation' (Schmidt, 2012: 40). Furthermore, Schmidt asserts that there is an affinity between new materialist work in general and liberal institutions promoting 'good governance' as a reaction to climate change. Both she suggests, put forward a view of the world as complex and unpredictable, where notions of human action or autonomy are an illusion, and both suggest that the best way to act in a world of multiple complex systems is to adapt to the current situation rather than to challenge existing structures. In this way, posthuman and new materialist arguments provide an ethical underpinning for neoliberalism (Schmidt, 2013).

These are very powerful critiques, not only of our work but also of the posthumanist / new materialist move. That there was a possibility of resignation to complexity was an issue that we had confronted and rejected in our previous work (Cudworth and Hobden, 2011: 179). Living in a complex world certainly adds to the problems of practice, but doesn't of itself imply that purposeful action is impossible. As we will see (in Chapter 5) there is a growing literature which addresses the question of policy making under complexity. While there is a range of different positions, none suggest that making policy is an irrelevance or not feasible under conditions of complexity, although there are radically different ideas about how complexity can be confronted. 
Our particular interest is not in state policy making, as we are sceptical about the capacity of states to bring about the radical transformations that we consider are necessary to confront the ecological issues that we face, but also because of states failure to tackle matters of global inequality.

The criticisms that have been made have prompted us to re-think and develop our perspective. Our project is to de-centre the human, and not to lose the possibility, in Schmidt's words 'to critically engage' with the sources of contemporary crises. And while we think that confronting complexity is an issue that needs addressing, it is not our view that this leaves us at the mercy of 'blind necessity'. Living creatures engage and change the world -- there would be no oxygen if not for photosynthesisers. Humans as a species have shown a particular capacity to transform the world - such that we now talk of an Anthropocene era - but they are not the first animals to change the planet, and probably won't be the last. To paraphrase and supplement Marx, creatures make the world, but not in circumstances of their choosing and not necessarily with the outcomes that they intended.

As we indicated at the start of this chapter, we confront two major crises: an ecological one that may make vast areas of the planet uninhabitable, and threatens civilisation itself, if not the species. At the same time, we are confronted by worldwide levels of inequality, which are not sustainable. The implications of the research on ecological footprint suggests that it is impossible everyone on the planet to enjoy the lifestyle of either Qatar, the United States, or Western Europe - indeed the level of consumption for most of us needs to be reduced rather dramatically. There needs to be a marked degree of re-thinking about what is and what is not possible. As 
a final twist to the puzzle, the evidence of the twentieth century is that the great human projects for change have not ended well: fascism, communism and liberalism. One is tempted to say 'get out of that one'.

In this book, we argue that any path out of this current morass will require as a minimum a re-thinking of our relation with the rest of nature - and we call this 'the emancipatory project of posthumanism'. We develop this project by addressing the following themes:

- $\quad$ In a world typified by complexity, how is it possible to pursue political projects?

- $\quad$ How have ideas about emancipation been developed and does the notion still hold relevance for the contemporary world order?

- What are the implications of differing posthuman/new materialist viewpoints for an emancipatory project?

We have chosen to call our project an emancipatory one, despite emancipation being a term which has been understood in many ways. In the next chapter we will discuss the notion of emancipation, both in a broader sense, and related to international relations and specifically critical approaches to the study of global politics. The development of the use of the term will be examined. The chapter will discuss the criticisms of the notion of an emancipatory project. It will also consider to what extent critical theory has failed to live up to its emancipatory goals. The chapter concludes with an assessment of the issues that an emancipatory posthumanism will need to address. 
The next two chapters assess the work within two areas of posthuman/new materialist literature. In Chapter 3 we look at the work which can be broadly described as 'enchanted materialism' or 'new vitalism'. Our interest here is in the work of Jane Bennett and William Connolly. While we see considerable overlaps between our work and this perspective, we will criticise it as being a liberal position that implies insufficient change to challenge the multiple crises we currently confront. Bennett argues that inorganic matter such as kerbside litter (trash) or an electricity grid, all exhibit force and vitality rendering them active, productive and self-creating. Bennett argues for a vital materialism which recognises the role of apparently inanimate matter affecting and configuring situations and events. In 'enchanted materialism' we consider that there is a tendency to minimise the differences between subjects and objects with this notion of a vitality which runs through both human and non-human matter. The political project of an enchanted materialism is the development of a more environmentally aware and cautious politics, which we would support, however, the chapter will argue that an analysis which prioritises a 'shared materiality of all things' does little to illuminate the operation of power both within and between species.

We find a similar disregard for the operation of power in William Connolly's work. Connolly argues for a politics of experimentation within the existing political framework, rather than for the development of a transformatory politics. Confronted with the political transitions that have occurred through 2016 and 2017, we find his optimism for the possibilities of change within the current political structures rather unconvincing. 
In Chapter 4 we turn to the work of Bruno Latour, and his writing on actor-network theory. Latour depicts the social world as an assembly of material entities and processes, constituted through the interactions of all kinds of matter (human and nonhuman) in the form of networks. Latour describes the emergence of apparently modern Western societies through the interaction of two processes -- purification and hybridization. The processes of purification involve the separation of the human world from the world of things and the construction of the world of nature and its scientific study; separate from the study of the social world with its selves, cultures and politics. Yet, despite our claims to modernity, our world is one of relative degrees of hybridization as we are caught in networks of interactions and relations between what Latour would understand as more or less natural and more or less social phenomena. Latour argues that within these networks, non-human matter is an 'actant'. This is both a counter to humancentric prejudice, and reflects our reality as one of the multitudes of species situated in a range of 'attachments' on planet earth.

We would agree with Latour's analysis of the embedded situation of humanity, yet as with Bennet's work, the effect of a network analysis is to flatten out relations between different actors and actants. This has the impact of obscuring power relations between different actors, and in particular the possibility of one actor to alter the context in which others act. While we acknowledge the basis of Latour's call for a 'Parliament of Things' we will argue that this remains a humancentric and inclusionary, rather than a posthumanist and transformatory project. 
That the outcomes of our actions may be different from our intentions is far from a novel idea. While complexity thinking has often focussed on the problems confronting policy makers (for example, Forrester, 1971), there is a developing literature on policy making under conditions of complexity. Chapter 5 will examine some of this research, which aims to think about how we might learn to live with complexity. We will argue that there is a spectrum of approaches to policy making under complexity. At one of the spectrum are those that argue that we can develop tools to manage complexity. For example, Sandra Mitchell suggests replacing traditional 'predict' and 'act' policies with processes of scenario evaluation and 'adaptive management'. At the other end of the spectrum are those who argue that we should 'let complexity rip'. In other words, exploit the characteristics of complexity to allow the best policy outcomes to emerge. Robert Axelrod and Michael Cohen (1999) argue that not only is it possible to make policy under conditions of complexity, complexity itself can be actively harnessed in pursuit of goals. While the analysis of policy making, and the development of policy making, when confronted by complexity, is a recent development, attempts to address policy making in conditions of complexity indicate the rejection of the idea that we confront a situation of 'blind necessity'.

In Chapters 6 and 7 we develop the foundations for the emancipatory project of posthumanism. In Chapter 6, we further expand our ideas on the specifics of a critically posthumanist political perspective, which we began in Posthuman International Relations (2011). The chapter reworks and reinvents established political concepts for a more-than-human-world, engaging animal studies, ecological feminism and plant theory. Within animal studies we will assess the arguments of 
those such as Peter Singer and Tom Regan, who have argued for an expansion of the notion of interests and rights to other animals, and the work of Donaldson and Kymlica who have expanded the range of understandings of human political relations with other animals, in particular citizenship. While feminist contributions to this debate have been varied, reflecting a multitude of feminist perspectives, they have shared a common concern with the precarious situation of other creatures and have drawn upon intersectional analysis to trace out multiple forms of oppression. Plant theorists have extended the debate on relations with the rest of nature beyond nonhuman animals, by posing the question of our ethical responsibilities to these very radical others. Here we focus in particular on Anna Tsing's recent work which uses the matsutake mushroom as a starting point for a reflection on living within the ruins of capitalism. The chapter then turns to an assessment of forms of transformatory politics. Hasana Sharp, drawing on the work of Spinoza argues for a Philanthropic Posthumanism, which sees the human species as neither superior nor inferior to the rest of nature. Lori Gruen suggests that we should acknowledge our entangled empathy with other species. For Gruen this is an alternative to the extension of rights across the species barrier advocated by Singer. By contrast Gruen's view is that we should begin with a notion of empathy, that acknowledges our entangled relations with the rest of nature and uses this as a starting point for reflection on the ethical implications that this generates. Our critique of human-centred and human-defined concepts of the political leads us away from 'zoopolis' in which non-human creatures are included to various degrees in an (albeit radically different) polity, and towards a notion of community. 
While Chapter 6 focuses on the possibilities of a transformation in relations between human and non-human nature, Chapter 7 engages with posthuman thought regarding the question of what it means to be human. The chapter begins with an assessment of the recent literature on civilization, and argues that the term civilization has been used as a direct way of establishing a distinction between human and non-human nature with the most 'civilised' being considered as those who are most divorced from the rest of nature. We examine writers such as Rose Bird and Plumwood who challenge this notion of civilization and propose that we engage with indigenous cosmologies. The latter part of the chapter examines a variety of suggestions for how we might rethink the human in the context of a more than human world. The chapter concludes with a call for a creaturely politics that stresses the embodied nature of 'the human' and our embedding in vital networks with other beings and things. Herein, there is a rather different politics of 'wellbeing' that is inclusive of living non-human being. This does not only imply a critical perspective on the human centred organisation of our economic organisation, our social practices and our ways of doing politics, it also requires a shrinking of the idea of 'the human' as we know it, and a transition to a more embodied 'animal' condition in which we humans share vulnerabilities with other creatures and living things.

In this context, what future(s) might be envisaged? In Chapter 8 we will outline our version of an emancipatory project of posthumanism in the form of a terraist manifesto. This manifesto rejects both universalistic projects and liberal approaches to resolving the current crises. Instead, drawing on the work of Simon Springer, we seek to 'fuck neoliberalism', by arguing against it, rejecting it, and examining alternatives. 
In looking to alternatives we focus in particular on posthuman communities as settings for exploring other ways of living with the rest of nature.

Our undertaking is a transformatory one. It is one that seeks to explore, experiment, and consider futures that are alternate to the current neoliberal path. We describe this as an emancipatory project, while acknowledging the baggage associate with the term. As we will see in the following chapter emancipation is a concept with many meanings and applications. Our purpose will be to tease out our own application of the idea. 